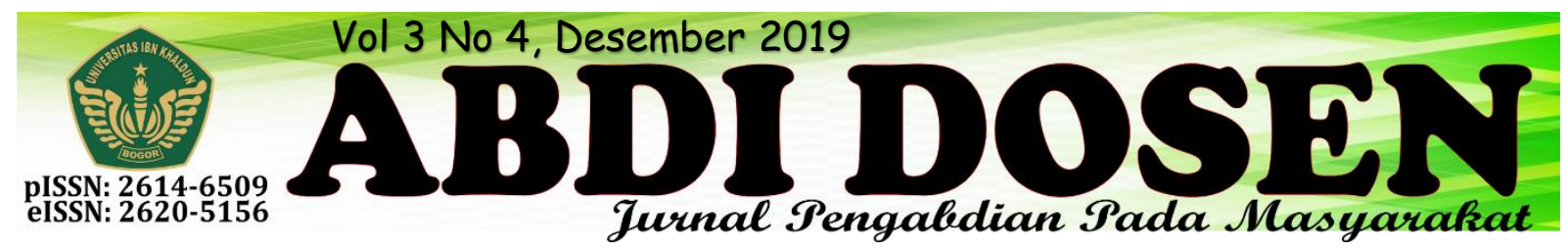

\title{
PEMBERDAYAAN MASYARAKAT MELALUI PENINGKATAN KUALITAS PENDIDIKAN, EKONOMI, KESEHATAN DAN LINGKUNGAN
}

\author{
Retno Triwoelandari ${ }^{1}$, Khoerul Fachri, Abdus Salam ${ }^{2}$ \\ retnotriwoelandari@fai.uika-bogor.ac.id \\ Fakultas Agama Islam Universitas Ibn Khaldun¹, Mahasiswa KKN Kelompok 26 Tahun $2018^{2}$
}

\begin{abstract}
ABSTRAK
Pengabdian masyarakat adalah suatu gerakan proses pemberdayaan diri untuk kepentingan masyarakat. Pengabdian masyarakat bersifat kontinual dan jangka panjang karena dalam membangun sebuah masyarakat dibutuhkan proses yang panjang. Banyak aspek yang harus di sentuh untuk menjadikan masyarakat itu lebih baik, karakternya, budidayanya, sampai pola pikirnya harus disentuh untuk benar-benar menciptakan suatu masyarakat yang lebih baik dan berkualitas. Pengabdian merupakan salah satu yang wajib kita laksanakan dari tiga tri dharma perguruan tinggi. KKN Tematik Terintegrasi 2018 UIKA Bogor. Mengedepankan asas kekeluargaan dan asas kemandirian. Asas itulah yang awal kita bangun untuk mencari informasi disekitar tempat kami melakukan kewajiban KKN ini. Membantu masyarakat menjadi lebih baik dan berkualitas ini dimaksudkan untuk membantu masyarakat dalam pelaksanaan pembangunan diberbagai bidang, terutama pendidikan, ekonomi, lingkungan dan kesehatan. Kelompok 26 ini melakukan kegiatan KKN tematik terintegrasi di salah satu desa yang berada di kecamatan parung tepatnya di Desa Waru Jaya. Penduduk desa waru jaya parung umumnya bergerak di bidang budidaya tanaman hias, ikan hias, dan produksi rumahan dan kain. Pemberdayaan masyarakat melalui peningkatkan kualitas pendidikan, ekonomi, kesehatan dan lingkungan masyarakat Waru Jaya
\end{abstract}

Kata Kunci : Pemberdayaan Masyarakat, Peningkatan Kualitas, Pendidikan, Ekonomi, Kesehatan, Lingkungan

\section{PENDAHULUAN}

Kuliah Kerja Nyata merupakan salah satu bagian dari sistem pendidikan dari lembaga Perguruan Tinggi, yang menempatkan mahasiswa di luar kampus agar mahasiswa hidup bersama di lingkungan masyarakat untuk membantu, mendampingi, dan memberdayakan masyarakat dalam potensi sumber daya alam lokal dan sumber daya manusia yang ada untuk mengatasi dan memberikan solusi dalam permasalahan masyarakat dengan jangka waktu tertentu. bagian dari sistem Pendidikan tinggi yang menempatkan Mahasiswa di luar Kampus agar mahasiswa hidup ditengah-tengah masyarakat bersama masyarakat untuk membantu dan mendampingi masyarakat memanfaatkan potensi sumberdaya alam lokal dan sumber daya manusia yang ada untuk mengatasi permasalahan masyarakat dalam kurun waktu tertentu.

KKN Tematik Terintegrasi UIKA Bogor merupakan sebuah tuntutan/ kewajiban bagi mahasiswa KKN Tematik 
Terintegrasi UIKA Bogor merupakan sebuah tuntutan/kewajiban bagi mahasiswa semester VII. Sasaran KKN Tematik Terintegrasi bagi masyarakat yakni untuk meningkatkan kesadaran masyarakat dengan berperan aktif dalam mengembangkan sumber daya pembangunan sesuai dengan fasilitas yang dimiliki. Lembaga Penelitian dan Pengabdian Masyakat (LPPM) UIKA Bogor telah melaksanakan KKN Tematik terintegrasi pada tahun 2017 di Kabupaten Bogor.

Kegiatan KKN Tematik Terintegrasi UIKA Bogor Tahun 2018 merupakan salah satu kegiatan untuk masyarakat dimana pada pelaksanaan kegiatan ini melakukan proses perencanaan sekaligus aksi program Pendampingan masyarakat baik pada aspek sosial, ekonomi, kesehatan, pendidikan, hukum, dan agama maupun teknologi tepat guna secara terpadu.

\section{Keadaan Geografis}

Desa Cijujung merupakan salah satu desa di wilayah kecamatan Cibungbulang kabupaen Bogor dengan Luas Wilayah 290 Hektar yang terbagi dalam 4 dusun, 10 rukun warga (RW), 25 rukun tetangga $(\mathrm{RT})$. Batas Wilayah Desa Cijujung adalah sebagai berikut:

\begin{tabular}{|c|l|c|}
\hline No & Keterangan & Berbatasan \\
\hline 1 & Utara & Karehkel \\
\hline 2 & Selatan & $\begin{array}{c}\text { Cimanggu 1, } \\
\text { Dukuh, Galuga }\end{array}$ \\
\hline 3 & Barat & Karehkel \\
\hline 4 & Timur & Ciaruteun Ilir \\
\hline
\end{tabular}

Pemanfaatan lahan/ penggunaan tanah di Desa Bojong Indah adalah sebagai berikut:

\begin{tabular}{|c|l|c|}
\hline No & \multicolumn{1}{|c|}{ Arah } & Luas/Ha \\
\hline 1 & $\begin{array}{l}\text { Perumahan/ } \\
\text { Pemukiman dan } \\
\text { Pekarangan }\end{array}$ & $77,5 \mathrm{Ha}$ \\
\hline 2 & Sawah & $45,6 \mathrm{Ha}$ \\
\hline 3 & Tegalan & $1,5 \mathrm{Ha}$ \\
\hline 4 & Jalan & $42,9 \mathrm{M}^{2}$ \\
\hline 5 & Pemakaman & $3,5 \mathrm{Ha}$ \\
\hline 6 & Kantor Desa & $250 \mathrm{M}^{2}$ \\
\hline 7 & Perkebunan & $25,5 \mathrm{Ha}^{-}$ \\
\hline \multicolumn{3}{|c|}{ Bidang Lingkungan, } \\
permasalahannya adalah sedikitnya \\
penerangan jalan, sehingga jika dalam \\
kondisi malam, mengakibatkan tabrakan.
\end{tabular}

\section{Kondisi Masyarakat}

Jumlah penduduk Jumlah penduduk

Desa Cijujung sampai akhir bulan Desember tahun 2018 tercatat sebanyak 10.696 Jiwa dengan jumlah 1.460 Kepala Keluarga (KK), terdiri dari:

\begin{tabular}{|c|c|c|}
\hline No & Jenis Kelamin & Jumlah \\
\hline 1 & Laki-laki & 5.722 Jiwa \\
\hline 2 & Perempuan & 4.989 Jiwa \\
\hline
\end{tabular}

Secara umum kondisi sosial politik serta ketentraman dan ketertiban di wilayah Desa Cijujung cukup baik dan terkendali. Dalam hal ini, kehidupan politik warga masyarakat dapat tersalurkan sesuai dengan aspirasinya seiring dengan bergulirnya reformasi dan banyaknya partai politik yang berkembang pada saat ini.

Berkaitan dengan masalah keamanan, dalam kurun waktu tahun 2018, telah terjadi pencurian sebanyak 2 kali. Pencurian pertama, yaitu pencurian sepeda motor milik warga, dan Pencurian kedua terjadi di lembaga sekolah SMPN 3 Cibungbulang, dengan kehilangan 5 unit komputer, dan 1 TOA Speaker. 
Dalam bidang kesehatan adalah disetiap RW terdapat posyandu, sehingga warga antusias untuk memeriksa kesehatan atau kegiatan posyandu lainnya. Namun untuk puskesmas hanya ada satu untuk 4 kelurahan. Sehingga untuk berobat di puskesmas warga merasa enggan, karena antrinya yang panjang.

\section{Tingkat Pendidikan Penduduk}

\begin{tabular}{|c|c|c|}
\hline No & Keterangan & Jumlah \\
\hline 1 & Belum Sekolah & 1742 \\
\hline 2 & Tidak Tamat SD & 37 \\
\hline 3 & Tamat SD/Sederahat & 721 \\
\hline 4 & Tamat SLTP/Sederajat & 1315 \\
\hline 5 & Tamat SLTA/Sederajat & 1055 \\
\hline 6 & Tamat Akademi & 74 \\
\hline 7 & Tamat S1 & 10 \\
\hline 8 & Tamat S2 & 2 \\
\hline 9 & Tamat S3 & 1 \\
\hline \multicolumn{2}{|c|}{ di Desa Cijujung dalam bidang } \\
\hline
\end{tabular}

pendidikan yaitu, masih rendahnya tingkat kesadaran dan kepedulian akan pentingnya pendidikan yang ditandai dengan masih banyak nya usia sekolah yang tidak sekolah, sehingga sebagian besar masyarakatnya tidak berpendidikan tinggi.

Selain itu di desa Cijujung masih banyak masyarakat yang belum bisa membaca, menulis dan berhitung khususnya untuk ibu-ibu berusia 20 tahun keatas.
Keadaan Ekonomi

\begin{tabular}{|c|c|c|}
\hline No & Keterangan & Jumlah \\
\hline 1 & Petani & 1007 \\
\hline 2 & Petani Pemilik & 870 \\
\hline 3 & Petani Penggarap Tanah & 688 \\
\hline 4 & Buruh Tani & 968 \\
\hline 5 & PNS & 15 \\
\hline 6 & TNI/POLRI & 3 \\
\hline 7 & Buruh Pabrik & 742 \\
\hline 8 & Pengrajin & 19 \\
\hline 9 & Tukang Bangunan & 379 \\
\hline 10 & Penjahit & 21 \\
\hline 11 & Tukang Ojek & 28 \\
\hline 12 & Bengkel & 13 \\
\hline 13 & Sopir & 47 \\
\hline 14 & Pekerja Serabutan & 4647 \\
\hline \multicolumn{3}{|c|}{ Desa Cijujung, } \\
\hline
\end{tabular}

penduduknya memproduksi sayur mayur seperti kangkung, bayam, sawi, terong dll. Sedangkan pemasarannya masih belum secara luas (mereka mengirim sayur mayur itu ke beberapa pasar yang ada di kabupaten bogor, misal pasar leuwiliang).

Dan sangat disayangkan para petani lebih menjual kepada tengkulak. Yang sebenarnya jika di inovasikan dapat di jadikan berbagai macam produk yang dapat bernilai jual tinggi.

Selain iu juga kurang adanya lembaga keuangan yang dapat menunjang terlaksananya kegiatan usaha masyarakat seperti koperasi simpan pinjam dan sebagainya. 


\section{METODE PELAKSANAAN}

\section{Tahap Pelaksanaan}

Tahapan pelaksanaan untuk kegiatan ini sebagaimana terlihat pada bagan sebagai berikut
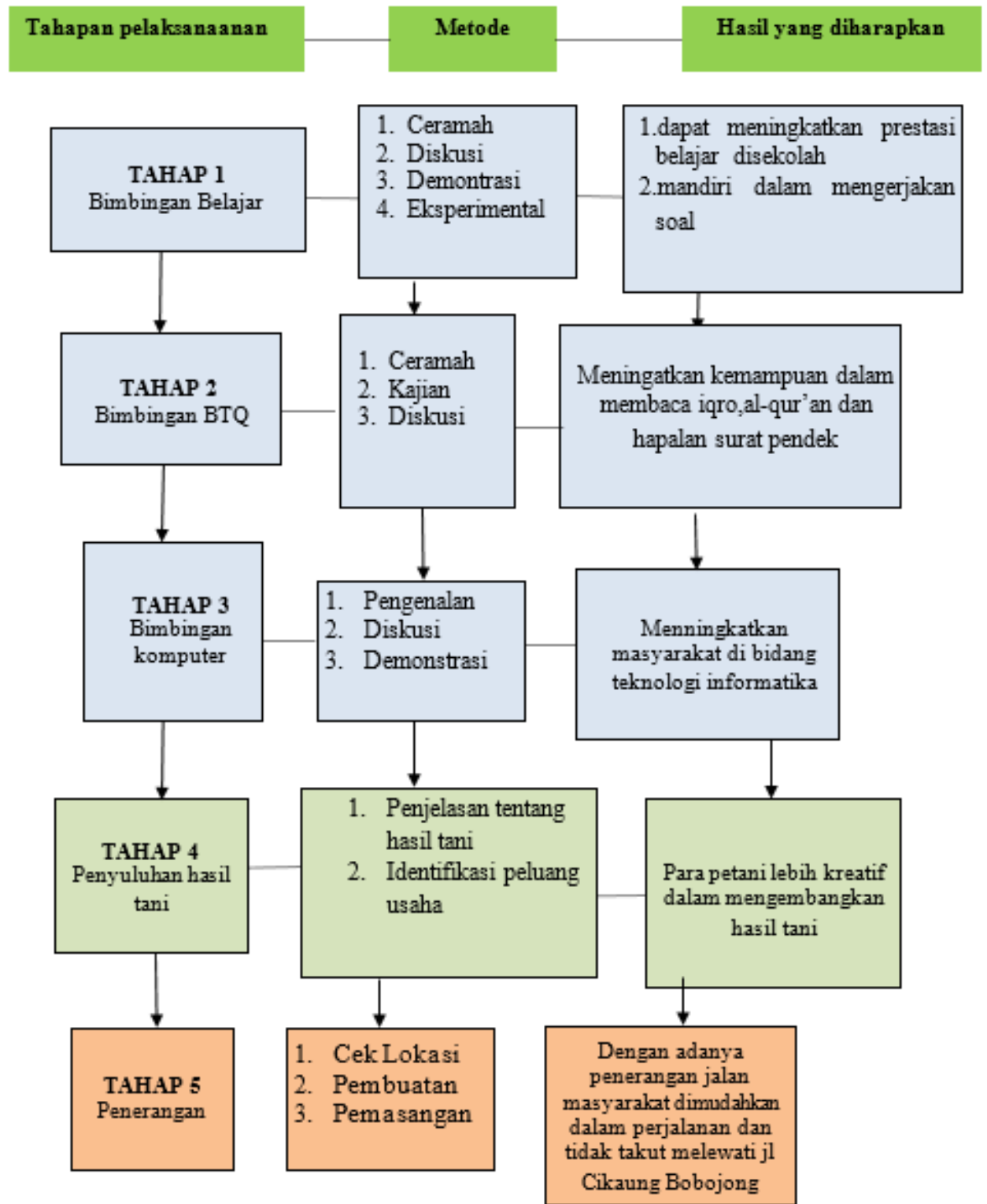

\section{Metodologi Penyelenggaraan KKN}

\section{Tematik Terintegrasi}

1. Pendekatan dan Strategi Umum

Untuk melaksanakan perluasan cakupan atau pengembangan terintegrasi dengan berbagai kegiatannya dilakukan secara bertahap, sesuai dengan strategi pentahapan pendekatan tiga dimensi, garis besarnya mencakup perluasan jangkauan, pembinaan, dan perlembagaan serta pembudayaan. Upaya-upaya itu dilakukan sesuai dengan kematangan masyarakat mengenai terintegrasi dan kegiatan yang dilaksanakannya.

Data yang dikumpulkan terdiri dari data primer dan sekunder, data primer adalah berbagai data dan informasi yang diperoleh secara langsung dari informasi maupun responden dilapangan yang merupakan pengurus dan anggota terintegrasi, data sekunder adalah berbagai data dan informasi yang diperoleh dari 
berbagai literatur maupun referensi yang terkait dengan tujuan dan sasaran penelitian, seperti laporan dan dokumen mengenai pemberdayaan keluarga dan masyarakat yang didapatkan dari jumlah dinas dan instansi pemerintah.

Data tentang aspek kelembagaan dan profil posdaya diperoleh melalui wawancara, observasi dan informan kunci yang merupakan mengelola masing-masing terintegrasi. Informasi tambahan diperoleh dari kepala desa, tokoh masyarakat, tokoh agama, dan kader serta anggota terintegrasi yang dipilih secara acak berdasarkan latar belakang pendidikan, kesehatan dan ekonomi,

\section{Metode Pengembangan Model}

Terintegrasi

Penyusunan Model Pembentukan

Terintegrasi

Kegiatan dilaksanakan dengan berbagai metode. Metode yang dimaksud antara lain adalah:

- Penyuluhan Penyadaran

- Pendampingan

Pelaksanaan kegiatan itu dibagi kedalam beberapa tahap, yaitu tahap persiapan, tahap pelaksanaan, tahap pendampingan dan evaluasi.

\section{Tahap Persiapan}

Tahap ini dilakukan dengan kegiatan penjajakan dan pendataan, penyusunan rencana kerja posdaya, dan pengembangan posdaya dengan implementasi berbagai perencanaan program kerja.

- Penjajakan dan Pendataan, diawali dengan serangkaian penelitian untuk menjajaki potensi, peluang dan kendala pembentukan terintegrasi dari berbagai sumber data, yaitu aparat desa, tokoh masyarakat, baik formal maupun nonformal, kepala sekolah, komite sekolah yang ada diwilayah yang akan dibentuk terintegrasi. Data diambil dengan cara wawancara langsung dan diskusi kelompok terarah(Focus Group Discussion).

- Rapat Project Terintegrasi, diagendakan untuk memilih tim kerja, menyusun program kerja, prioritas dan menetapkan kesekretariatan posdaya. Program prioritas yang dikembangkan dalam wadah posdaya adalah bidang yang banyak berpengaruh pada peningkatan kesejahteraan masyarakat dan sekaligus berkaitan erat dengan indikator pendekatan IPM yaitu:

1. Bidang Pendidikan: meliputi pengajian untuk anak-anak TPQ dan juga mengajar bahasa Arab dan bahasa Inggris, penyuluhan pentingnya pendidikan bagi masyarakat.

2. Bidang Lingkungan: meliputi mengadakan Jum'at gotong royong, instalasi penerangan jalan Bobojong, menyelenggarakan perlombaan pada HUT-RI ke 73

3. Bidang Kesehatan meliputi penyuluhan cuci tangan bagi pemilah pemulung sampah, pemberian vitamin A dan menimbang bayi bagi BATITA senam Aerobik bagi ibu-ibu masyarakat, membantu program PUSKESMAS dalam program mawas diri, penyuluhan Stunting bagi BATITA.

4. Bidang Pemberdayaan Ekonomi meliputi penyuluhan kewirausahaan hasil tani.

\section{Perencanaan Dan Sosialisasi KKN}

\section{Tematik Terintegrasi}

- Survei Tempat

Kegiatan survei ini dilaksanakan sebanyak dua kali, yaitu pada 28 Juli 2018 dan 4 Agustus 2017 . Pada kegiatan survei pertama kami disambut oleh pihak 
perangkat Desa untuk selanjutnya kami koordinasi dengan perangkat desa untuk mendapatkan posko di Desa tersebut. Kegiatan survei tempat ini juga bermaksud untuk mensosialisaikan maksud dan tujuan kegiatan $\mathrm{KKN}$ TERINTEGRASI yang akan dilaksanakan selama 30 hari kurang dari tanggal 7 Agustus 2018 sampai dengan 5 September 2018.

\section{Penerimaan di Desa Cijujung}

Kegiatan penerimaan ini dilaksanakan saat pemberangkatan $\mathrm{KKN}$ Tematik Terintegrasi Universitas Ibn Khaldun Bogor 2018 pada hari Selasa tanggal 07 Agustus 2018 yang bertempat di posko. Kegiatan ini dihadiri oleh Kades beserta bapak tokoh masyarakat (bpk RT dan RW 04) Cikaung Bobojong. Pada penerimaan ini, semua anggota $\mathrm{KKN}$ dikenalkan satu persatu kepada perangkat Kades dan tokoh masyarakat Cikaung Bobojong. Selain itu memperkenalkan kondisi terkini di Cikaung Bobojong.

- Masyarakat

Sebelum melaksanakan kegiatan KKN, kami melaksanakan sosialisasi terlebih dahulu dengan aparat pemerintah Desa, ketua RW, RT dan tokoh masyarakat, serta masyarakat umumnya yang berada di desa tersebut. Selanjutnya, kami mendatangi dan sosialisasi ke PAUD, Sosialisasi Ke Sekolah SMPN 3 Cibungbulang, dan Madrasah Tsanawiyah dan Aliyah Cinta Rasul dan sosialisasi ke pesantren Nurul Huda Al Hasanah. Hal ini bertujuan untuk menjelaskan maksud kedatangan kami untuk melaksanakan KKN selama 30 hari di desa tersebut.

\section{Pendekatan yang digunakan dalam kegiatan ini adalah:}

i. Pendekatan religius, yaitu pendekatan religius yang dilakukan oleh kelompok
26 Cijujung Cibungbulang ini dengan melakukan pendekatan kepada tokohtokoh agama yang ada dilingkungan sekitar RW 04 selanjutnya melakukan kunjungan kepada ketua Karang Taruna (Persatuan Pemuda Cikaung Bobojong) pendekan ini guna membantu dan bekerja sama dalam setiap program yang kita akan dilaksakan.

ii. Pendekatan Sosial yaitu pendekatan sosial ini dilakukan dengan mengujungi dan menjalin silaturahmi dengan bapak kepala Desa, RW 04 dan beberapa RT yang ada di RW 04 ada pula untuk warganya itu sendiri ikut serta pada setiap majelis-majelis yang ada di Desa Waru Jaya.

iii. Pendekatan organisasi, yaitu pendekatan yang dilakukan oleh kelompok 18 yang bekerjasama dengan Yayasan Pendidikan Islam Nurul Hidayah 54 dan Karang Taruna di Desa Waru Jaya tersebut.

iv. Pendekatan berdasarkan karakter masyarakat, yakni pembinaan yang dilakukan akan disesuaikan dengan karakter masyarakat. Partisipasi Masyarakat dalam Pelaksanaan Program Partisipasi masyarakat yang dapat dilakukan dalam kegiatan ini adalah sebagai berikut:

1. Mengikuti setiap kegiatan yang terdapat dalam program kerja KKN Kelompok 18.

2. Mempersiapkan tempat untuk acara seminar dan penyuluhan.

3. Membantu dalam kegiatan baik secara materi atau non-materi.

4. Membantu dalam pengumpulan atau mengajak warga dalam setiap acara.

5. Ikut berpartisipasi dalam setiap kegiatan yang diselenggarakan 


\section{Langkah Evaluasi}

Evaluasi yang akan dilakukan terdiri dari:

a. Evaluasi proses, yang terkait dengan perencanaan, pelaksanaan dan monitoring kegiatan. Evaluasi proses akan dilakukan setiap dua pekan bersama dengan masyarakat.

\section{HASIL DAN PEMBAHASAN}

\section{Bidang Pendidikan:}

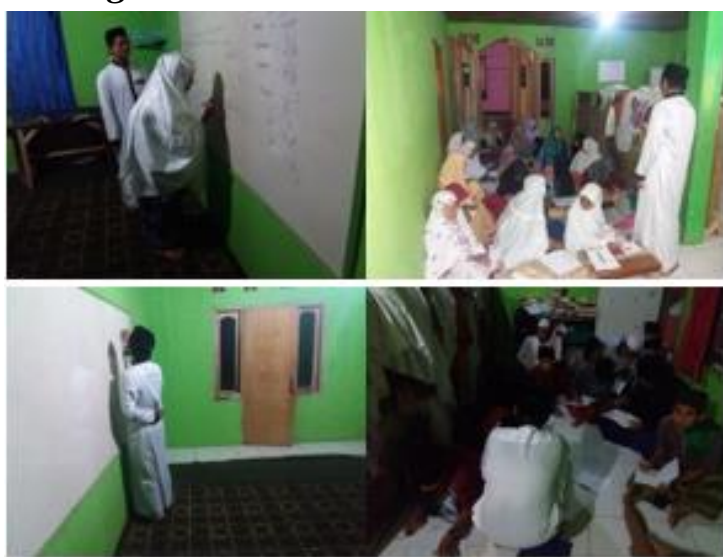

Pengajaran Bahasa Arab di Ponpes Nurul

Huda Al-Hasanah untuk santri dan santriwati ponpes Nurul Huda Al Hasanah setiap hari Minggu dan Hari Selasa

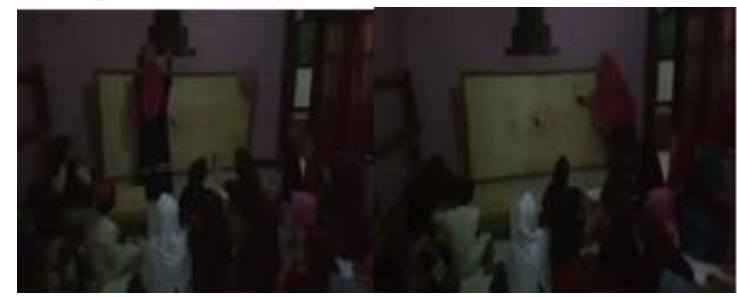

Pengajaran Bahasa Inggris di Ponpes Nurul Huda Al Hasanah setiap hari Sabtu dan Hari Senin
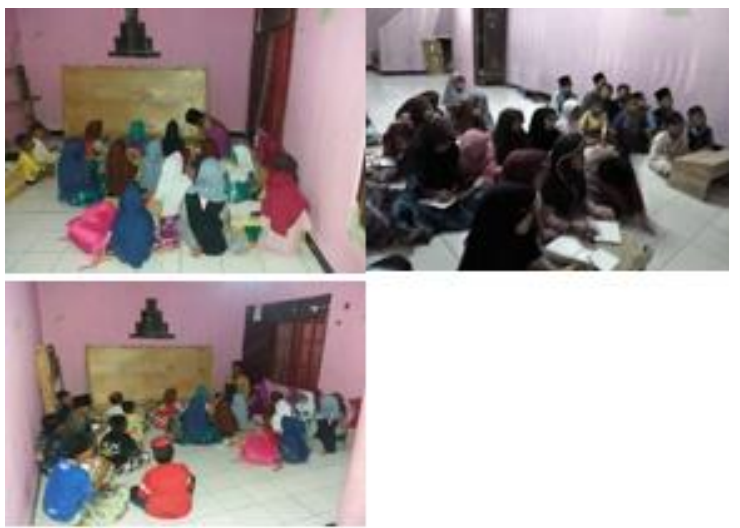

b. Evaluasi hasil, yang akan dilaksanakan setelah kegiatan dilaksanakan. Evaluasi hasil ditujukan untuk menguji pemahaman masyarakat terkait dengan pentingnya pendidikan untuk meningkatkan kualitas SDM dan kesadaran lingkungan masyarakat di Kp Cikaung Bobojong RW 04

Pengajian BTQ bagi anak-anak SD di Ponpes Nurul Huda Al-Hasanah setiap hari Sabtu sampai Rabu

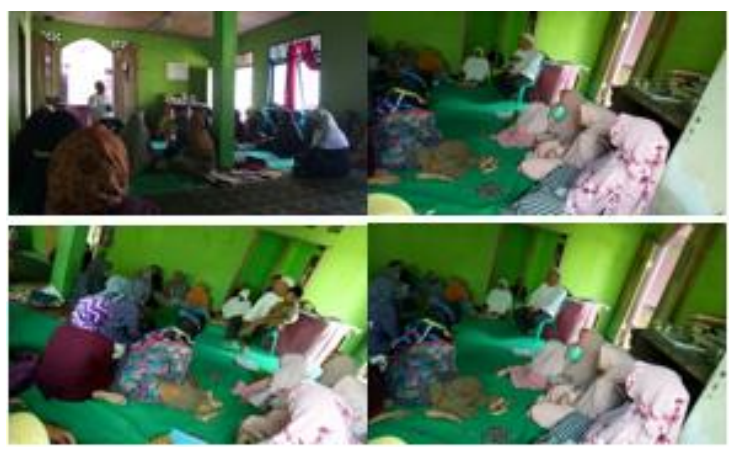

Penyuluhan Pentingnya Pendidikan Bagi Masyarakat Kampung Cikaung Bobojong pada hari Selasa Tanggal 21 Agustus 2018

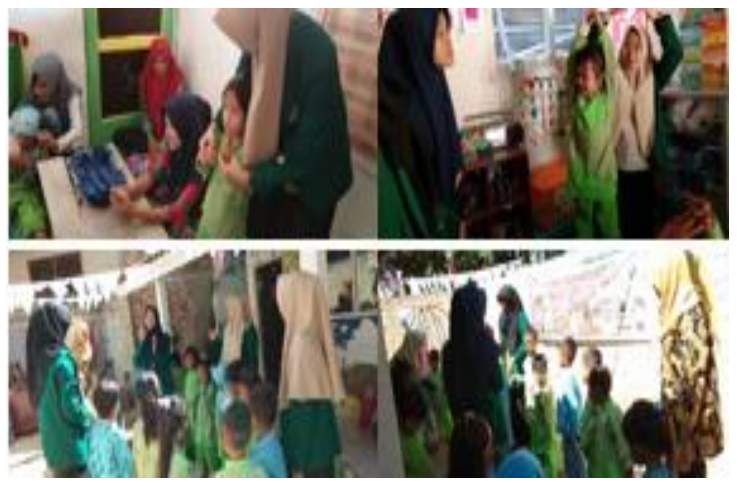

Pengajaran PAUD bagi anak-anak umur 56 tahun Cikaung Bobojong di PAUD AnNida setiap hari Rabu, Kamis dan Jumat 


\section{Bidang Ekonomi:}
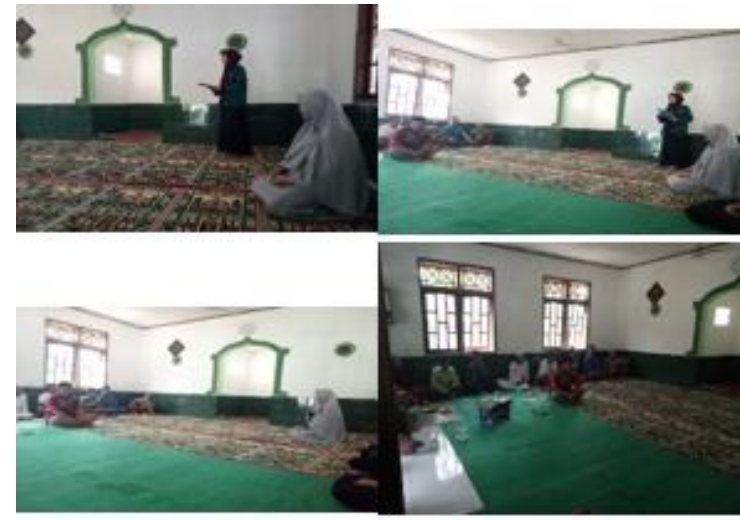

Penyuluhan Kewirausahaan (hasil tani) bagi para petani RW 04 di Mushollah ArRahman, Cikaung Bobojong, Cijujung pada hari Senin Tanggal 13 Agustus 2018

\section{Bidang Kesehatan:}

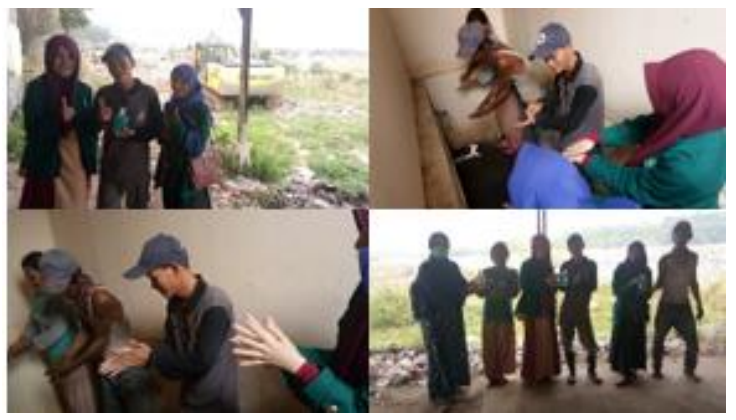

Cuci Tangan bagi pemilah sampah di tempat pembuangan akhir sampah Galuga pada hari Jum'at tanggal 24 Agustus 2018.

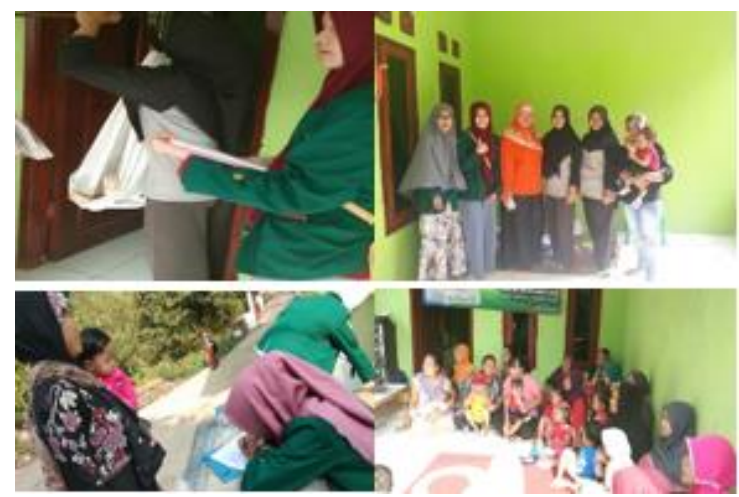

Pemberian vitamin dan timbang bayi bagi batita RW 04 Cikaung Bobojong, Cijujung di Posyandu Melati 4 pada hari Sabtu tanggal 25 Agustus 2018.

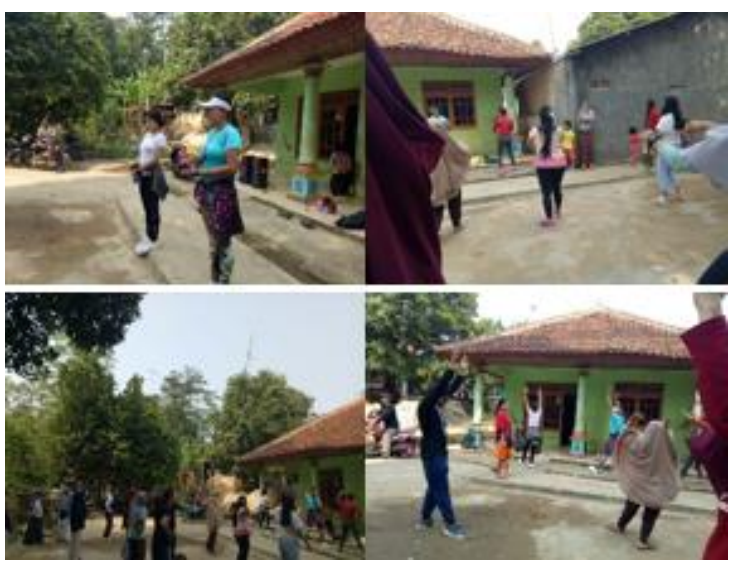

Senam Aerobik bagi ibu-ibu masyarakat RT 01 RW 04 Cikaung Bobojong, Cijujung di Lapangan Badminton Cikaung Bobojong pada hari Sabtu tnggal 25 Agustus 2018.
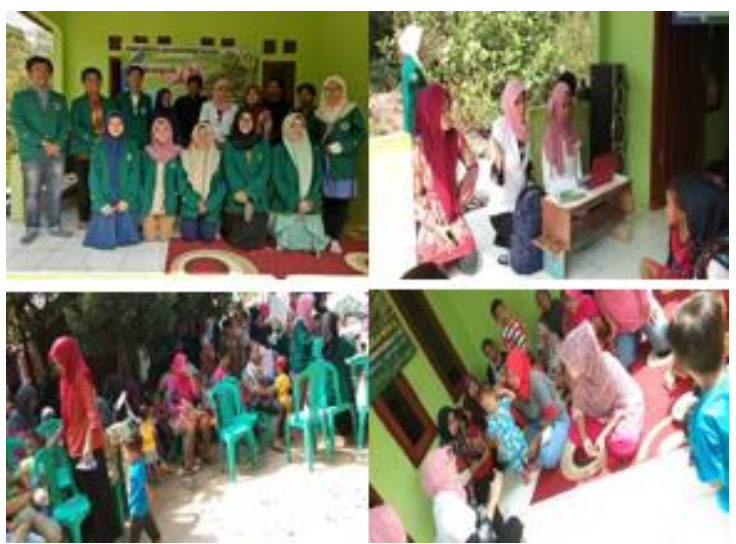

Penyuluhan Stunting bagi ibu-ibu RW 04 Cikaung Bobojong, Cijujung di Posyandu Melati 4 pada hari Jum'at tanggal 31 Agustus 2018. 
Bidang Lingkungan:

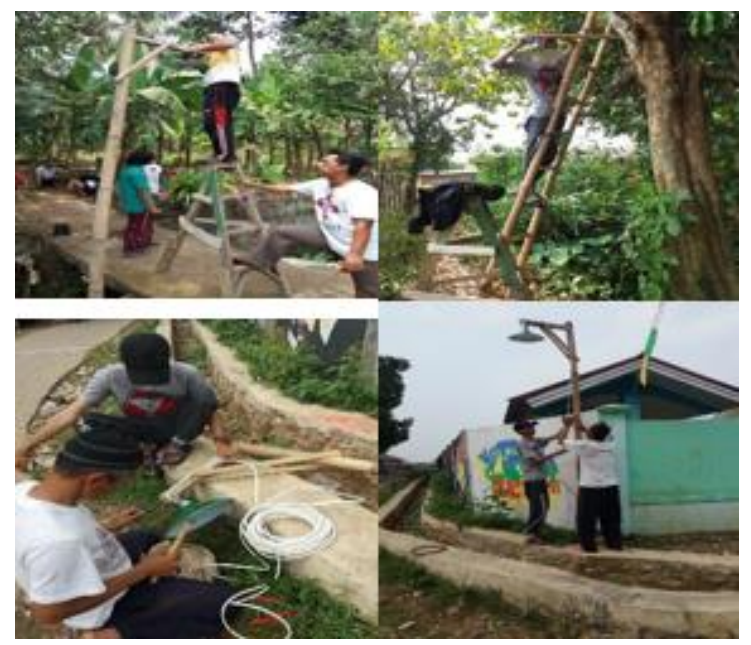

Pembuatan dan pemasangan penerangan untuk menerangi dan memudahkan warga melewati jalan pada malam hari di jalan raya Cikaung Bobojong dan di jalan setapak di RT 01 dan RT 03 RW 04 Cikaung Bobojong, pada hari Selasa tanggal 14 Agustus 2018.

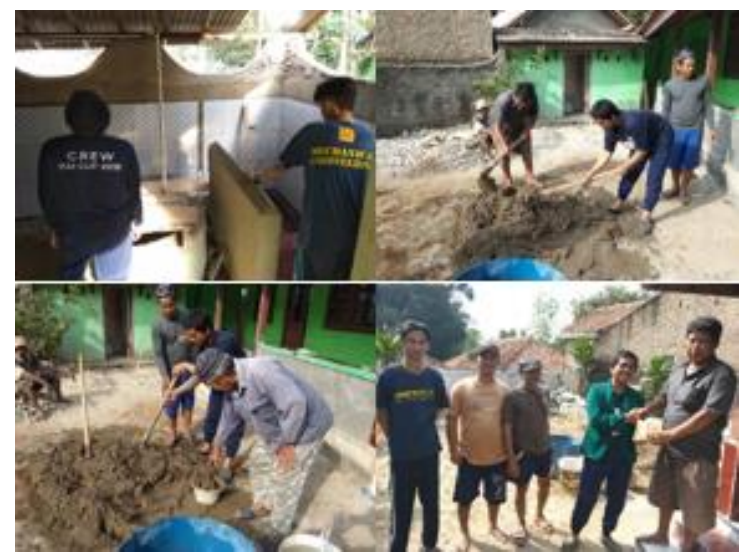

Kerja Bakti dalam pembangunan Mushola Ar-Rahman RT 01 RW 04 Cikaung Bobojong pada hari Jum'at 12 Agustus 2018.
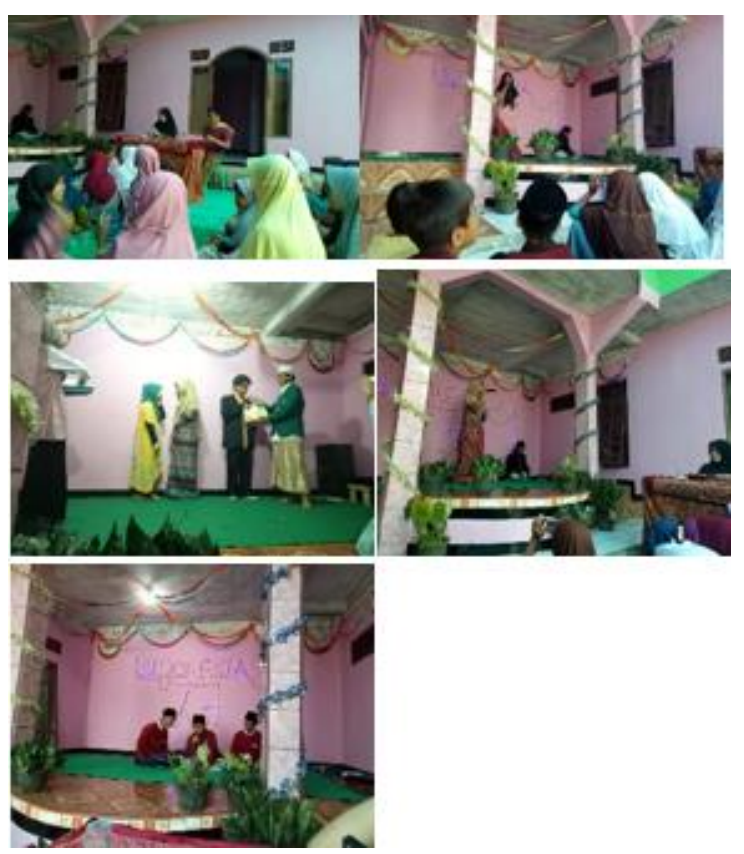

Perlombaan 17 Agustusan di Ponpes Nurul Huda Al-Hasanah pengembangan bakat santri dan santriwati Ponpes Nurul Huda pada hari Jum'at dan Sabtu tanggal 17 dan 18 Agustus 2018.

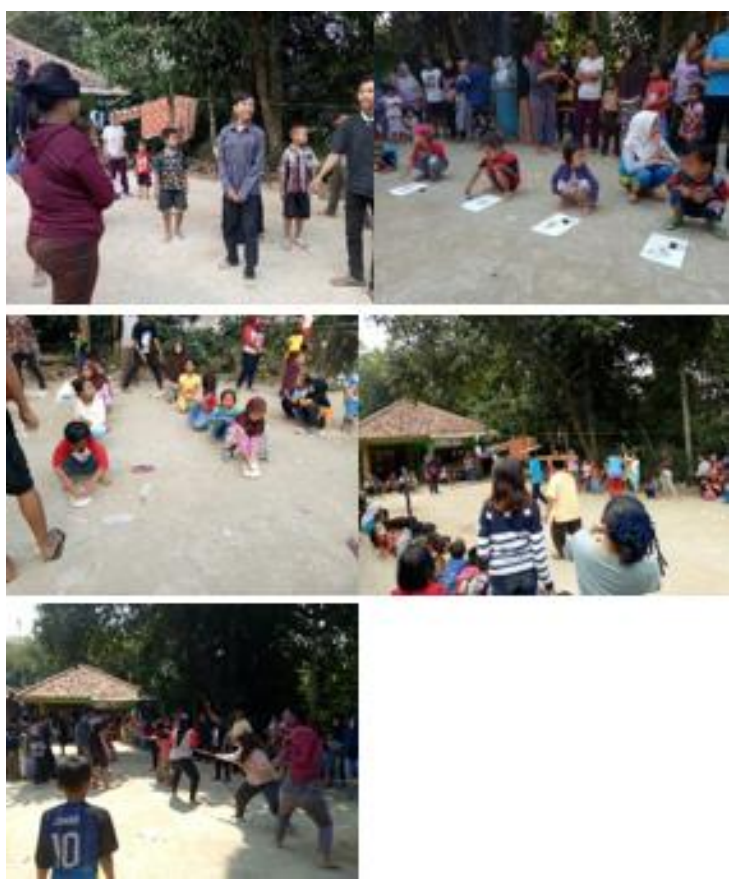

Perlombaan 17 Agustusan di lapangan Badminton RT 01 RW 04 Cikaung Bobojong bagi Masyarakat Cikaung Bobojong pada hari Sabtu tanggal 18 Agustus 2018. 

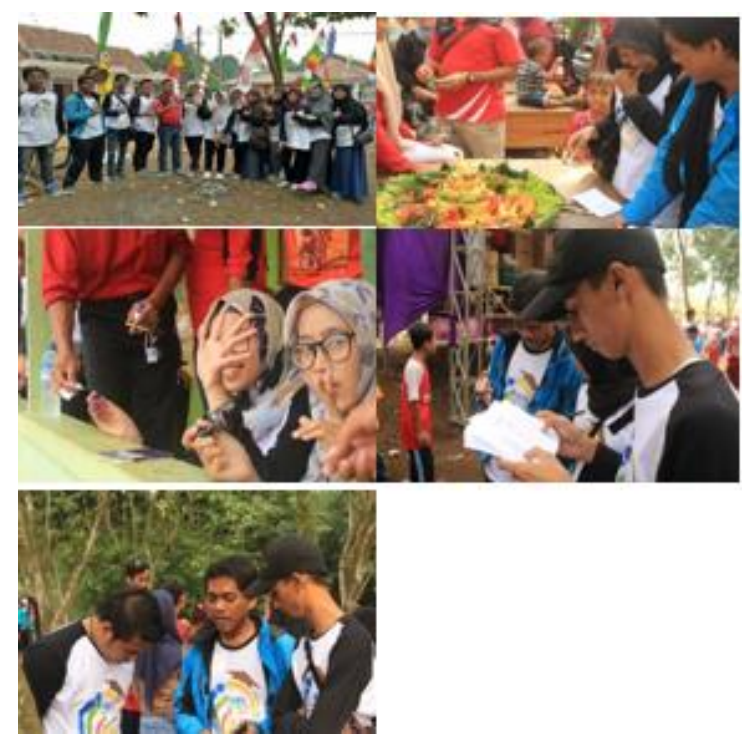

Pesta Rakyat bagi masyrakat Cijujung bekerjasama dengan Kades Cijujung

\section{KESIMPULAN}

Secara umum dengan melihat kinerja rekan-rekan semuanya dalam upaya mensukseskan kegiatan KULIAH KERJA NYATA TEMATIK TAHUN 2018 sangat kami apresiasi dan memberikan penghargaan yang sebesar-besarnya kepada seluruh anggota KKN 58 DESA LEUWIMEKAR Bogor dengan penuh keikhlasan , tanggung jawab dan komitmennya secara sungguh-sungguh. Kami sadar bahwa segala bentuk kekurangan kami itu tidak terlepas dari kebodahan kami juga selaku Mahasiswa yang masih dalam berproses mencari nilainilai kebenaran, kami juga sadar bahwa segala bentuk kelebihan yang kami berikan itu tidak terlepas dari kehendak yang maha kuasa yang senantiasa memberikan kemudahan kepada umatnya.

\section{Dampak Bagi Masyarakat}

Kuliah Kerja Nyata (KKN) adalah implementasi dari pengabdian masyarakat.yang merupakan salah satu unsur Tri Dharma perguruan tinggi: yaitu pendidikan dan pengajaran, penelitian dan pengabdian masyarakat. Program kkn ini beserta jajarannya dalam memeriahkan HUT RI ke- 73 di lahan kosong Cikaung Tengah pada hari Minggu tanggal 26 Agustus 2018.

berjalan dengan baik walaupun masih terdapat kendala-kendala. Namun semua kendala yang kami alami terasa indah dijalani dengan adanya kebersamaan dalam sebuah kelompok. Dengan menanamkan rasa hormat, penghargaan serta pengertian dari setiap anggota kelompok dan dengan masyarakat. Dengan hal itu seluruh kegiatan atau program yang dijalankan terasa ringan. Sehingga timbul keakraban antara mahasiswa kkn dengan masyarakat seperti tokoh-tokoh penting (KADES, ketua RW, ketua RT, ketua Karang Taruna, Ustad, dan Ustadzah), ibu-ibu, pemudapemudi, santri dan santriwati.

Adapun dampak dari setiap program yang telah kami laksanakan

a. Pengajaran Bahasa Arab

Dengan adanya pengajaran bahasa Arab, para santri dan santriwati di Pesantren Nurul Huda Al-Hasanah mampu mengenal kosakata bahasa Arab (walaupun hanya sedikit), kemudian mampu bercakap bahasa Arab.

b. Pengajaran Bahasa Inggris 
Dengan adanya pengajaran bahasa Arab, para santri dan santriwati di Pesantren Nurul Huda Al-Hasanah mampu mengenal kosakata bahasa Inggris (walaupun hanya sedikit), kemudian mampu bercakap bahasa Inggris.

c. Pengajaran di PAUD

Dengan adanya pengajaran di PAUD memudahkan para pengajar di PAUD An-Nida dalam proses pembelajaran, dan anak-anak PAUD mampu berani dan terampil dengan adanya kita.

d. Penyuluhan Pentingnya Pendidikan

Hadirnya penyuluhan "Pentingnya Pendidikan" agar masyarakat Cikaung Bobojong sadar dengan dunia pendidikan formal, selain itu orangtua mendorong dan mendukung anak-anak dalam pendidikan formal agar anakanak mereka kelak dewasa sukses.

e. Penyuluhan Kewirausahaan (Hasil Tani)

Hadirnya dengan adanya penyuluhan kewirausahaan (hasil tani) masyarakat petani cikaung bobojong paham dalam memasarkan hasil taninya sendiri dan kreatif dalam memproduksi hasil tani nya sendiri seperti keripik bayam, keripik singkong dll.

f. Cuci tangan bagi pemilah sampah Program ini hadir agar para pemilah sampah memahami pentingnya cuci tangan dengan memakai sabun antiseptic setelah memilah sampah. Supaya para pemilah sampah terhindar dari penyakit, yang timbul dari makanan yang tersentuh dengan tangan yang masih kotor atau banyak bakterinya.

g. Pemberian vitamin dan penimbangan bayi

Hal ini merupakan program yang sangat penting bagi ibu yang memiliki
BATITA (bayi tiga tahun ke bawah). Agar para ibu memperhatikan perkembangan bayi dari pola makan dan berat badannya.

h. Senam Aerobik

Senam Aerobik ini merupakan kegiatan olahraga bagi masyarakat cikaung bobojong akan pentingnya badan sehat tubuh bugar untuk pola kehidupan yang sehat.

i. Penyuluhan stunting

Penyuluhan ini hadir bagi ibu-ibu yang memiliki BATITA maupun BALITA supaya ibu-ibu mengetahui bagaimana gizi yang baik saat masih dalam kandungan sampai anak-anak, selain itu penting bagi kesehatan dan kesejahteraan anak-anak serta mencegah berat badan bayi lahir rendah, kematian ibu dan kematian bayi.serta sesuai indeks masa tubuh anak sesuai usianya.

j. Penerangan Jalan (PJ)

Adanya penerangan jalan untuk memudahkan bagi masyarakat cikaung bobojong dan masyarakat luar dapat melintasi jalan dengan terang dan supaya masyarakat tidak takut untuk melintasinya.

k. Perlombaan 17 Agustusan di pondok pesantren Nurul Huda Al-Hasanah, dan di RT 01 Cikaung Bobojong Dengan adanya perlombaan 17 Agustusan di Pondok Pesantren Nurul Huda AlHasanah, agar para santri dan santriwati mampu bersaing dengan kawannya sendiri, kemudian ajang mengembangkan bakat santri dan satriwati. Selain itu juga, bagi warga RT 01 Cikaung Bobojong agar mereka saling, sportifitas dalam bertanding, saling bekerjasama, dan berani tampil. 


\section{SARAN}

Untuk pemerintahan desa cijujung agar mendorong dan mendukung anak-anak desa Cijujung untuk berpendidikan tinggi minimal sma atau sederajat, agar mereka kelak ketika ingin bekerja dengan mudah

\section{DAFTAR PUSTAKA}

Administrasi Profil Desa CIjujung.

Petunjuk Pelaksanaan KKN Tematik Terintegrasi 2018 Universitas Ibnu Kholdun Bogor, Uika Press.

Amir, FR, SA Nasution, Pemberdayaan Masyarakat Melalui Kegiatan Pendidikan, Agama, Sosial, Ekonomi, dan Kesehatan, Qardhul

diterima. Selain Itu lebih peduli dengan kebersihan lingkungan, serta memfasilitasi koperasi untuk masyarakat petani, agar mereka mandiri menjual hasil tani mereka.

Hasan: Media Pengabdian kepada Masyarakat, Vol 3.1, April 2017

Fandatiar, Galuh ,Supriyono Supriyono, Fajar Nugraha, Rancang Bangun Sistem Informasi Kuliah Kerja Nyata (KKN) pada Universitas Muria Kudus, SIMETRIS; Jurnal Teknik Industri, Mesin, dan Ilmu Komputer, Vol 6.1 (2015). 